\title{
Outcomes of Periodontal Treatment in Diabetes Mellitus Patients at Kiruddu Referral Hospital in Uganda. A Prospective Cohort Study
}

Haruna Kiryowa ( $\sim$ kiryowa2005@yahoo.com )

Makerere University

\section{Erisa Mwaka}

Makerere University

William Buwembo

Makerere University

lan Munabi

Makerere University

Charles Rwenyonyi

Makerere University

Mark Kaddumukasa

Makerere University

\section{Research Article}

Keywords: Diabetes Mellitus, Periodontal Disease, Non-surgical Periodontal Treatment, Glycemic control, HBA1c

Posted Date: October 6th, 2021

DOI: https://doi.org/10.21203/rs.3.rs-954002/v1

License: (c) (1) This work is licensed under a Creative Commons Attribution 4.0 International License. Read Full License 


\section{Abstract}

Introduction: Periodontitis is a common complication of diabetes mellitus associated with poor glycemic control. The relationship between periodontal disease and glycemic control in patients with diabetes mellitus remains unclear. This study set out to determine the outcomes of periodontal treatment in diabetic patients in Uganda.

Methods: Using a cohort study design, 41 adult diabetic patients with periodontal disease were enrolled and followed up for 3 months. Fasting blood sugar, glycated hemoglobin levels, pocketprobing depth, bleeding and clinical attachment loss at baseline and 3 months after periodontal treatment were determined. Gingival crevicular fluid was assessed to detect presence of Porphyromonas gingivalis, Aggregatibacter actinomycetemcomitans, Bacteroides forsythus and Fusobacterium nucleatum. Data were analyzed using $\mathrm{R}$ version 4.10. Mean differences were calculated to determine effect of treatment and multiple logistic regressions was used to determine association between $\mathrm{Hba} 1 \mathrm{c}$ and the different variables.

Results: Of the 41 participants, $61 \%$ were females while $39 \%$ were males. The average age was 49.2 years $(S . D=11.2)$ while the mean BM1 was $27.8(S . D=4.8)$. Overall, there was a reduction in the average number of teeth with bleeding sites, those with pockets and the frequencies of selected bacteria except Fusobacterium nucleatum at 3 months after periodontal treatment. Following periodontal treatment, 39\% of the participants had an improvement in their glycemic control (mean HbA1c reduction of 1.86) with age $<47.1$ years, diabetic duration less than 1.6 years, BM1 $<27.7$ and HBA1C $>8.9$ at baseline being positively associated with this improvement.

Conclusion: Treating periodontal disease in diabetic patients especially those with HBA1c $<9.0$ can improve glycemic control. However, larger studies need to be conducted to ascertain why some patients fail to attain an improved metabolic control following this intervention.

\section{Introduction}

Diabetes mellitus is increasingly becoming a plague to mankind affecting about $6.8 \%$ of the population worldwide(1). In 2017, approximately 462 million people were affected by type two diabetes mellitus. Global prevalence is projected to rise to 7079 cases per 100,000 by 2030 (2). About $43.7 \%$ of diabetic patients have chronic periodontitis which is associated with poor blood glucose control in this population $(3,4)$. Periodontal disease is more prevalent and severe in diabetic patients than the nondiabetics (5). Periodontitis a risk factor for poor glycemic control and development of diabetic complications (6). Periodontitis and diabetes establish a two way pathway, and each one, if untreated, could promote or exacerbate complications of each other (7). Treatment of periodontal disease in patients with diabetes mellitus has been shown to have an effect on glycemic control (8). Systemic reviews and meta-analysis have supported the effectiveness of periodontal therapy in improving glycemic control and periodontal status in patients with diabetes mellitus and periodontitis. patients. (9, 
10). Reports from one study indicated that non-surgical periodontal treatment markedly improved glycaemic control with an attributable reduction of 2.2 points of glycated haemoglobin $(\mathrm{HbA1c})$ in poorly controlled T2D patients in a sub Saharan setting (8). Control of periodontal disease may enhance glycaemic control in patients with type 2 diabetes. In turn, improved glycaemic control may contribute to a better control of periodontal disease(11). However, in most studies, effects of periodontitis and its treatment on diabetes metabolic control are not clearly defined and results of the studies remain controversial. It is recommended to carry out further studies to ascertain this effect (12). The objective of this study was to determine outcomes of periodontal treatment on periodontal status and metabolic control in diabetic patients attending an outpatient clinic at a tertiary hospital in Uganda.

\section{Materials And Methods}

\section{Study setting}

The study was conducted from Kiruddu National Referral Hospital located in Makindye division of Kampala district. The Hospital runs a number of specialized clinics, with the diabetic clinic running every Wednesday. The clinic receives about 200 to 300 diabetic patients every Wednesday.

\section{Study design}

This was a cohort study involving 59 participants with diabetes mellitus and periodontal disease. 18 participants were lost to follow up. Reasons for loss to follow up included the corona virus pandemic that led to some participants migrating to rural areas, the uncertain political environment as this was period for presidential elections and the covid -19 SOPs like a ban on public transport.

\section{Participant recruitment and study procedure}

Inclusion criteria were; participants with confirmed diabetes mellitus diagnosis, aged 18 years and above diagnosed with periodontal diseaseand provision of written informed consent.All participantswho were pregnant, those receiving broad spectrum antibiotics or had a history of periodontal treatment in the last 6 months were excluded from the study.

Apre tested study tool developed by the investigators was administered to record socio- demographic characteristics, diabetichistory like duration of diabetes and diabetic medication and factors associated with periodontal disease which included oral hygiene practices, history of smoking. Weight in Kilograms and height in $\mathrm{m}^{2}$ were measured to calculate the BMI. The values for BMI were recorded as $<18$ :

underweight, 18.5-24.9: normal, 25-29.9: overweight and >30: obese(13). Venous blood was collected and analyzed to determine fasting blood sugar levels andHbA1c levels. The cut off value for good glycemic control was 6.5 and values above this were recorded as poor glycemic control (14).

An oral examination was then carried out by a dental surgeon using a dental mirror and a calibrated periodontal probe to determine the Community Periodontal Index value (CPI) and the Clinical Attachment Loss (CAL) from 6 sites namely upper central incisor (11), lower central incisors (31), upper right first or 
second molar (16/17), lower right first or second molar (46/47), upper left first or second molar (26/27) and lower left first or second molar (36/37). The data wererecorded in the Oral Health Assessment form for Adults (WHO, 2013). The CPI values were recorded as 0 for normal, 1 for bleeding, 2 for calculus, 3 for pockets less than $4 \mathrm{~mm}$ and 4 for pockets greater than $4 \mathrm{~mm}$. The CAL levels were recorded as distance from the cemento-enamel junction to the gingival margin and values were assigned as follows 0: 0-3mm, 1: 4-5mm, 2: 6-8mm, 3: 9-11 mm and 4: $12 \mathrm{~mm}$ or more. Samples of gingival crevicularfluid were collected using a paper point and transferred to a Cryo vial container containing a buffer. These were then transported in ice packs to the laboratory where DNA extraction was carried out using the Quick- gDNA method by ZymoResearch. PCR detection was then carried out in three stages: Amplification, Annealing and Elecrophoresis to determine the presence of four common periodonto-pathogenic bacteria namely Porphyromonas gingivalis, Aggregatibacter actinomycetemcomitans, Bacteroides forsythus and Fusobacterium nucleatum.

\section{Data Analysis}

Data was entered in Microsoft excel, cleaned and exported to R (version 4.10) for analysis. The results obtained at baseline and after 3 months of follow up were compared. Mean differences in HbA1c levels, number of teeth with bleeding sites, number of teeth with pockets and four common periodontopathogenic bacteria were determined. The Paired t-test was used to determine the association of the different outcomes with $\mathrm{HbA} 1 \mathrm{c}$ levels following periodontal treatment and a $p$-value of $<0.05$ was considered statistically significant. Multi-level regression analysis was used to determine the factors associated with improvement in glycemic control following periodontal treatment.

\section{Results}

\section{Baseline characteristics of the study participants}

Of the 41 participants, sixty-nine percent were female and the average age was 49.2 years (range $=39.0$ years, S.D $=11.2$ years). Over two thirds of the participants were either overweight or obese. Only one person reported cigarette smoking and he had been doing so for more than 10 years. Seventy-five percent of the participants had attended either primary or secondary education with only fourteen-point six percent reporting no school attendance. Ninety-seven-point seven percent had periodontitis and the mean HbA1c was 9.0 (SD=2.9). (See Table 1 in appendix i). 
Table 1

A summary of Baseline characteristics of the study participants

\begin{tabular}{|ll|}
\hline Characteristics & Frequency (\%) \\
\hline BMI & $1(2.4)$ \\
\hline$<18.0$ (Underweight) & $10(24.4)$ \\
\hline $18.5-24.9$ (Normal) & $19(46.4)$ \\
\hline $25-29.9$ (Overweight) & $11(26.8)$ \\
\hline$>30$ (Obese) & \\
\hline Monthly income (Ugshs) & $13(31.7)$ \\
\hline None & $18(43.9)$ \\
\hline$<400,000$ & $8(19.5)$ \\
\hline $400,000-1,000,000$ & $2(4.9)$ \\
\hline$>1,000,000$ & \\
\hline Daily frequency of brushing & $2(4.9)$ \\
\hline None & $16(39.0)$ \\
\hline Once & $23(56.1)$ \\
\hline Twice & $27(65.9)$ \\
\hline Method of teeth cleaning & $4(9.8)$ \\
\hline None & $2(4.9)$ \\
\hline Tooth brush & $2(4.9)$ \\
\hline Tooth brush and tooth paste & $37(90.2)$ \\
\hline Diabetic medication & \\
\hline Oral & $10.8)$ \\
\hline Insulin & \\
\hline Both & \\
\hline Diabetic duration & \\
\hline$<1$ year & \\
\hline $2-5$ years & \\
\hline $6-10$ years & \\
\hline
\end{tabular}




\begin{tabular}{|ll|}
\hline Characteristics & Frequency (\%) \\
\hline$>10$ years & $13(31.7)$ \\
\hline CAL & \\
$0(0-3 \mathrm{~mm})$ & $20(48.8)$ \\
$1(4-5 \mathrm{~mm})$ & $10(24.4)$ \\
\hline $2(6-8 \mathrm{~mm})$ & $4(9.8)$ \\
$3(9-11 \mathrm{~mm})$ & $2(4.9)$ \\
\hline $4(12 \mathrm{~mm}+)$ & $5(12.2)$ \\
\hline
\end{tabular}

\section{Effect of periodontal treatment on periodontal status of study participants}

Before treatment, forty participants had periodontitis and only one participant had normal periodontal status. Following periodontal treatment, the number of participants with periodontitis reduced drastically to $39.1 \%$, the majority of these having only mild forms of the disease. The mean difference in number of teeth with bleeding sites was $6.49(95 \% \mathrm{Cl}=5.09-7.88, t=9.39, \mathrm{p}=0.000)$ while that for the number of teeth with pockets $4.34(95 \% \mathrm{Cl}=3.03-5.65, t=6.71, \mathrm{p}=0.000)$. There was a thus a statistically significant improvement in the periodontal status of the study participants following periodontal treatment (Table 2).

Table 2

Periodontal status of the study participants at baseline and after three months

\begin{tabular}{|lll|}
\hline & Baseline & \multicolumn{1}{c|}{ After 3 months } \\
\hline Periodontal status (CPI) & \multicolumn{1}{l}{ Frequency (percent) } \\
\hline Normal (0) & $1(2.4)$ & $21(58.5)$ \\
\hline Calculus (2) & $0(0)$ & $1(2.4)$ \\
\hline Mild periodontitis (3) & $25(61.0)$ & $12(29.3)$ \\
\hline Severe periodontitis (4) & $15(36.6)$ & $4(9.8)$ \\
\hline Total & $\mathbf{4 1 ( 1 0 0 )}$ & $\mathbf{4 1 ( 1 0 0 )}$ \\
\hline
\end{tabular}

\section{Effect of periodontal treatment on selected periodonto-pathogenic bacteria}

Following periodontal treatment, there was a reduction in proportion of participants with $P$. gingivalis from $48.7-31.7 \%$, those with $A$. actinomycemcomitans from $36.6-24.4 \%$, those with B.forsythus from 
43.9-12.2\% but no change in the proportion of those with F.nucleatum. There was thus a general reduction in the subgingival microbiota following periodontal treatment. (Table 3)

Table 3

Effect of periodontal treatment on selected periodonto-pathogenic bacteria

\begin{tabular}{|lll|}
\hline Bacteria & Frequency (\%) & \\
\hline Poryphromonas gingivalis & Baseline & After 3 months \\
\hline Aggregatibacter actinomycetemcomitans & Present: $20(48.7)$ & Present: $13(31.7)$ \\
& Absent: $21(51.3)$ & Absent: 28 (68.3) \\
\hline Bacteroides forsythus $15(36.6)$ & Present: $10(24.4)$ \\
& Absent: $26(63.7)$ & Absent: $31(75.6)$ \\
\hline Fusobacterium nucleatum & Present: $18(43.9)$ & Present: $05(12.2)$ \\
& Absent: $23(56.1)$ & Absent: $36(87.8)$ \\
\hline & Present: $03(7.3)$ & Present: $03(7.3)$ \\
\hline & Absent: $38(92.7)$ & Absent: $38(92.7)$ \\
\hline
\end{tabular}

\section{Effect of periodontal treatment on glycemic control}

Generally, there was no difference in HBA1c levels following periodontal treatment (mean difference = $0.024, t=0.06, p=0.096)$. However, in $39 \%$ of the participants, there was a significant change in HbA1c levels following periodontal treatment (mean difference $=1.85, t=2.84, p=0.007$ ). Multilevel regression analysis, while controlling for individual, in these patients identified age younger than 47 years $(t=-0.79$, $p=0.440)$, duration of diabetes less than 1.7 years $(t=-0.47, p=0.640)$, BMI less than $27.7(t=-1.83, p=$ $0.075)$ and $\mathrm{HbA} 1 \mathrm{c}$ levels $>8.9(\mathrm{t}=2.03, \mathrm{p}=0.005)$ at base line to be associated with improved glycemic control. However, this association was only statistically significant for high $\mathrm{HbA} 1 \mathrm{c}$ levels at base line.

\section{Association between the different variables with $\mathrm{HbA1c}$}

Table 4 provides a summary of the final model multilevel regression modeling containing the set of variables that were retained in relation to their effect of the $\mathrm{HbA} 1 \mathrm{c}$ levels controlling for the participant. What stands out in this final model was that the presence of Fusobacterium nucleatum (Fn) was associated with a significant 2.14 reduction in $\mathrm{HbA} 1 \mathrm{c}$ levels keeping all other values in the model constant. Overall, the presence of Porphyromonasgingivalis (Pg) and Bacteroides forsythus (Bf) were each associated with an increase in the HbA1c levels. On the other hand, Aggregatibacter actinomycetemcomitans (Aa) was associated with a decrease in the levels of HbA1c. For these other bacteria it is important to note that these effects were not significant. It is also important to note that there was an interaction between the presence of Aggregatibacter actinomycetemcomitans (Aa) and 
having high random sugar associated with a -0.75 reduction in $\mathrm{HbA} 1 \mathrm{c}$ levels ( $p$ value $=0.70$ ). On average the intervention led to a 0.23 -unit reduction in the levels of HbA1c compared to baseline for all participants. This was not significant. Respondents with a high random blood sugar levels had on average 3.00 units more than those with normal random blood sugar.

Table 4

A table showing the association between the different variables with $\mathrm{HbA1c}$ levels.

\begin{tabular}{|llllll|}
\hline & Value & Std.Error & DF & t-value & p-value \\
\hline (Intercept) & 6.14 & 1.27 & 37 & 4.82 & $\mathbf{0 . 0 0}$ \\
\hline FnYes & -2.14 & 0.94 & 36 & -2.29 & $\mathbf{0 . 0 3}$ \\
\hline PgYes & 0.24 & 0.49 & 36 & 0.50 & 0.62 \\
\hline BfYes & -0.86 & 0.59 & 36 & -1.45 & 0.15 \\
\hline AaYes & 1.07 & 1.86 & 36 & 0.57 & 0.57 \\
\hline rbs2High & 3.00 & 1.32 & 37 & 2.28 & 0.03 \\
\hline Treatment.Yes & -0.23 & 0.32 & 36 & -0.52 & 0.61 \\
\hline Sex M & 0.69 & 0.68 & 37 & 1.01 & 0.32 \\
\hline AaYes: rbs2High & -0.75 & 1.94 & 36 & -0.39 & 0.70 \\
\hline
\end{tabular}

\section{Discussion}

This study reports the outcomes of periodontal treatment in diabetic patients in Uganda namely number of teeth with pockets, those with bleeding sites, frequencies of four periodonto-pathogenic bacteria and metabolic control determined by hbA1c levels. Generally, there was a drastic decline in number of teeth with pockets and those with bleeding sites. In addition, the frequencies of the bacteria decreased as well as an improvement in metabolic control in thirty-nine percent of the participants, three months after periodontal treatment.

Periodontal treatment has been reported to improve periodontal status (15). Brauchle et al (2013) reported a positive effect of periodontal treatment on oral health quality of life with a decrease in probing pocket depth of $>3 \mathrm{~mm}$ from $76 \%$ at baseline to $27.6 \%$ after treatment (16). Huang et al, 2016 also reported that patients on comprehensive periodontal treatment exhibited shallow pockets, less bleeding on probing and improved PCR(17). Periodontal treatment involves removal of plaque, calculus deposits and granulation tissue there by reducing the occurrence of the signs of gingivitis and periodontitis(18). This is in line with our findings that noted a decline in number of teeth with pockets by ninety-one percent and a decrease in proportion of participants with periodontitis from ninety-seven-point six percent to thirty-nine-point one percent. 
Periodontal treatment whether surgical or non-surgical has been demonstrated to decrease the median relative proportions and frequencies of periodonto-pathogenic bacteria (19). These bacteria have been shown to decrease at 2 months and 4 months following periodontal treatment (20). Our study noted a decrease in the frequencies of all the tested bacteria except Fusobacterium nucleatum. This is in contrast to a study that reported a significant decrease in all the tested bacteria following periodontal treatment except for Aggregatibacter actinomycetemcomitans (21). The reasons for this discrepancy are not well explained. One study identified smoking as an important factor for differences in changes in subgingival biodiversity following periodontal treatment (22). However, from our study, only one participant was a smoker and this small number cannot be statistically used to explain this variation. Despite these discrepancies, it is basic knowledge that periodontal treatment involves removal of plaque and calculus which are the reservoirs for periodonto-pathogenic bacteria (23). It is thus effective in reducing the proportions of these bacteria thereby improving the morbidity of patients with periodontitis.

Periodontal treatment whether associated with or without antibiotics can improve periodontal status of patients with diabetes mellitus (24). However, in majority of studies, this effect remains controversial. Vergnes et al, 2018 reported that periodontal treatment had no clinical effect on glycemic control (25) while Baeza et al, 2020 demonstrated a reduction in HBA1c levels by $0.56 \%$ following periodontal treatment (26). Findings from three studies revealed no significant differences in HB1Ac levels following periodontal treatment (27). Our study demonstrated an improvement in $\mathrm{Hba} 1 \mathrm{c}$ levels in $39 \%$ of the participants. The factors associated with this improvement were young age, shorter duration of diabetes mellitus, BMI less than 27.7 and high HBA1c levels at base line. This is partly in agreement with Kaur et al, 2015 who reported that although non-surgical periodontal therapy improved glycemic control and periodontal health in patients with type two diabetes, patients with poor baseline glycemic control had less clinical improvement than those with good glycemic control (28). Actually, a study conducted among veterans with poorly controlled diabetes mellitus reported no effect on glycemic control 4 months following periodontal treatment(29). Our study also identified short duration of diabetes mellitus and BMI as one of the factors associated with improvement in glycemic control. This is in agreement with Fiseha et al, 2018 who reported long duration of diabetes and Chetouia et al, 2020 who reported longer duration of diabetes and BMI to be associated with poor glycemic control $(30,31)$. It thus imperative to say that periodontal treatment can improve metabolic control in a number of diabetic patients. However, other factors need to be investigated and adequately addressed so as to improve morbidity of patients living with diabetes mellitus.

\section{Conclusion}

Non-surgical periodontal treatment can be effective in improving periodontal status and metabolic control in a significant number of patients with diabetes mellitus and periodontitis. However, further studies need to be conducted to ascertain why some patients do not experience an improvement in their metabolic control following periodontal treatment. 


\section{Declarations}

\section{Ethical approval and consent}

The study was performed in accordance with the relevant guidelines and regulations as approved by the Makerere University School of Biomedical Sciences Research and Ethics Committee (MAK SBS-REC: SBS726) and The Uganda National Council of Science and Technology (UNCST: HS106ES). Informed consent was obtained from all study participants and confidentiality was always maintained.

\section{Consent for Publication}

This is not applicable to this manuscript.

\section{Availability of data and materials}

The datasets generated and analyzed during the current study will be available from the corresponding author on request.

\section{Competing interests}

The authors declare that they have no competing interests.

\section{Funding}

This study was sponsored by the Government of Uganda through the Makerere University Research and Innovation Fund (MAK-RIF 1).

\section{Authors' contribution}

HK designed the study, contributed to writing the manuscript including the literature review, analyzed the data and contributed to interpretation of the results. EM, MK, IM, WB and CR provided overall supervision, revised the manuscript and provided additional interpretation of the results. IM analyzed the data, wrote additional sections of the manuscript and provided additional interpretation of the results. All the authors were actively involved in proof reading the manuscript.

\section{Acknowledgement}

We would like to extend our sincere appreciation to MAK-RIF for having sponsored this study, the Administration of Kiruddu Referral hospital for having granted us permission to use the diabetic clinic and all the patients of Kiruddu hospital diabetic clinic who participated in this study.

\section{References}

1. Khan MAB, Hashim MJ, King JK, Govender RD, Mustafa H, Kaabi JA. Epidemiology of Type 2 Diabetes - Global Burden of Disease and Forecasted Trends. Epidemiology and Global Health. 
2020;10(1):107-11.

2. Khan MAB, Hashim MJ, King JK, Govender RD, Mustafa H, Kaabi JA. Epidemiology of Type 2 Diabetes - Global Burden of Disease and Forecasted Trends. Journal of Epidemiology and Global Health. 2020;10:107-11.

3. Deshpande K, Jain A, Sharma R, Prashar S, Jain R. Diabetes and periodontitis. Journal of Indian Society of Periodontology. 2010;14(4).

4. Hong M, Kim HY, Seok H, Yeo CD, Kim YS, Song JY, et al. Prevalence and risk factors of periodontitis among adults with or without diabetes mellitus. Korean J Intern Med. 2016;31:910-9.

5. Llambés F, Arias-Herrera S, Caffesse R. Relationship between diabetes and periodontal infection. World J Diabetes. 2015;6(7):927-35.

6. Taylor GW, Borgnakke. WS. Periodontal disease: associations with diabetes, glycemic control and complications. Oral Dis. 2008;14(3):191-203.

7. Naiff $P$, Carneiro V, Guimaraes MdC. Importance of Mechanical Periodontal Therapy in Patients with Diabetes Type 2 and Periodontitis. International Journal of Dentistry. 2018;2018.

8. Tsobgny-Tsague N-F, Lontchi-Yimagou E, Nana ARN, Tankeu AT, Katte JC, Dehayem MY, et al. Effects of nonsurgical periodontal treatment on glycated haemoglobin on type 2 diabetes patients (PARODIA 1 study): a randomized controlled trial in a sub-Saharan Africa population. . BMC Oral Health 2018;18(28).

9. Wang XX, Han X, Guo X, Luo X, Wang D. The Effect of Periodontal Treatment on Heamoglobin A1c Levels of Diabetic Patients: A Systemic Review and Meta-Analysis. PLoS ONE 2014;9(9).

10. Teshome A, Yitayeh A. The effect of periodontal therapy on glyceamic control and fasting plasma glucose level in type 2 diabetic patients: Systematic review and meta-analysis. BMC Oral Health. 2016;17(31).

11. Bascones-Martinez A, Matesanz-Perez P, Escribano-Bermejo M, -Moles M-ÁG, Bascones-llundain J, Meurman J-H. Periodontal disease and diabetes-Review of the literature. Med Oral Patol Oral Cir Bucal. 2011;16:722-9.

12. Llambés F, Arias-Herrera S, Caffesse. R. Relationship between diabetes and periodontal infection. World J Diabetes. 2015;6(7):927-35.

13. Nuttall FQ. Body Mass Index Obesity, BMI, and Health: A Critical Review. Nutrition Today. 2015;50(3):117-28.

14. Sherwani SI, Khan HA, Ekhzaimy A, Masood A, Sakharkar MK. Significance of HbA1c Test in Diagnosis and Prognosis of Diabetic Patients. Biomarker Insights. 2016;11:95-104.

15. Koromantzos PA, Makrilakis K, Dereka X, Katsilambros N, Vrotsos IA, Madianos PN. A randomized, controlled trial on the effect of non-surgical periodontal therapy in patients with type 2 diabetes. Part I: effect on periodontal status and glycaemic control. J Clin Periodontol. 2011;38(2):142-7.

16. Brauchle F, Noack M, Reich E. Impact of periodontal disease and periodontal therapy on oral healthrelated quality of life. Int Dent J. 2013;63(6):306-11. 
17. ay K-CH, Lai C-H, Huang C-F, Lu H-K. A comprehensive periodontal treatment project: The periodontal status, compliance rates, and risk factors. Journal of Dental Sciences. 2016;11:182-8.

18. Shaddox LM, Walker CB. Treating chronic periodontitis: current status, challenges, and future directions. Clinical, Cosmetic and Investigational Dentistry. 2010.

19. Pedrazzoli V, Kilian M, Karring T, Kirkegaard E. Effect of surgical and non-surgical periodontal treatment on periodontal status and subgingival microbiota. J Clin Periodontol. 1991;18(7):555-66.

20. F D, HX M, QQ L, YB Z, XH F, L Z. Effect of periodontal mechanical treatment on periodontal pathogenic bacteria in gingival crevicular fluid of chronic periodontitis patients. Beijing Da Xue Xue Bao Yi Xue Ban. 2010;42(2):202-6.

21. Grzech-Leśniak K, Gaspirc B, Sculean A. Clinical and microbiological effects of multiple applications of antibacterial photodynamic therapy in periodontal maintenance patients. A randomized controlled clinical study Photodiagnosis and Photodynamic Therapy. 2019;27:44-50.

22. Meulman T, Casarin RCV, Peruzzo DC, Giorgetti AP, Barbagallo A, Casati MZ, et al. Impact of supragingival therapy on subgingival microbial profile in smokers versus non-smokers with severe chronic periodontitis. Journal of Oral Microbiology. 2012;4(1).

23. Lovegrove JM. Dental plaque revisited: bacteria associated with periodontal disease Journal of the New Zealand Society of Periodontology. 2004;87:7-21.

24. Pérez-Losada F-d-L, Jané-Salas E, Sabater-Recolons M-d-M, Albert Estrugo-Devesa, Segura-Egea J-J, López-López J. Correlation between periodontal disease management and metabolic control of type 2 diabetes mellitus. A systematic literature review. Med Oral Patol Oral Cir Bucal. 2016;21(4):440-6.

25. JN V, T C, A V, S L-D, F M-S, V B-B, et al. The effects of periodontal treatment on diabetic patients: The DIAPERIO randomized controlled trial. J Clin Periodontol 2018. 2018;45(11):1150-63.

26. BAEZA M, MORALES A, CISTERNA C, CAVALLA F, JARA G, ISAMITT Y, et al. Effect of periodontal treatment in patients with periodontitis and diabetes: systematic review and meta-analysis. Journal of Applied Oral Science. 2020;1(13).

27. Wang T-F, Jen I-A, Chou C, PH D, Lei Y-P. Effects of Periodontal Therapy on Metabolic Control in Patients With Type 2 Diabetes Mellitus and Periodontal Disease. A Meta-Analysis. Medicine. 2014;93(28).

28. PK K, SC N, R R, R KS, S T. Periodontal and glycemic effects of nonsurgical periodontal therapy in patients with type 2 diabetes stratified by baseline HbA1c. J Oral Sci. 2015;57(3):201-11.

29. Jones JA, Miller DR, Wehler CJ, Rich SE, Krall-Kaye EA, McCoy LC, et al. Does periodontal care improve glycemic control? The Department of Veterans Affairs Dental Diabetes Study J Clin Periodontol 2007;1:46-52.

30. Fiseha T, Alemayehu E, Kassahun W, Adamu A, Gebreweld1 A. Factors associated with glycemic control among diabetic adult out-patients in Northeast Ethiopia. BMC Res notes. 2018;11(316).

31. Chetouia A, Kaoutara K, Elmoussaouia S, Boutahara K, Kardoudia AE, Chigra F, et al. Prevalence and determinants of poor glycaemic control: a cross-sectional study among Moroccan type 2 diabetes patients. International Health 2020. 2020:1-8.

Page 12/12 